\title{
GI Emergencies in the ICU
}

\author{
Sreeram Parupudi MD, FACP, FACG
}

\begin{abstract}
Patients in intensive care units (ICU) for nonGI related disorders are frequently at risk for developing $\mathrm{Gl}$ emergencies. The most common etiologies include upper or lower GI bleeding, acute mesenteric ischemia, acute cholecystitis, acute pancreatitis, and acute hepatic failure.
\end{abstract}

\section{GI bleeding}

- $\quad$ The morbidity and mortality of GI bleeding developing in patients hospitalized for other reasons is higher than in those presenting primarily with $\mathrm{GI}$ bleeding. $^{2}$

- In the absence of known or overt liver disease, non-variceal UGI bleeding related to gastroduodenal erosions or ulcers is common.

- Stress prophylaxis with $\mathrm{H} 2$ blockers or proton pump inhibitors (PPI) is recommended after major abdominal, cardiac, orthopaedic, or neurosurgeries. $^{3}$

- $\quad$ Frank blood in NG lavage, a significant drop in hematocrit, or persistent hemodynamic compromise warrant urgent endoscopy. Otherwise, initiation of PPI therapy and close clinical monitoring might suffice.

- Lower GI bleeding in ICU patients should prompt evaluation for ischemic colitis by multidetector computed tomography (MDCT).

- Mankongpaisarnrung et al discuss a patient presenting with a GI bleed in this issue of the Southwest Respiratory and Critical Care Chronicles reiterating the role of risk stratification in the appropriate management to identify the low risk patients who can be triaged to optimal outpatient management while recognizing the high risk patients needing in-patient care.

\section{Acute mesenteric ischemia}

- Manifestations include unexplained abdominal distension, absence of bowel sounds, diarrhea, and/or lower GI bleeding.

- A quick review of history must check for atrial fibrillation, presence of hypercoagulable states (prior DVT/PE), lowflow states (CHF), or conditions associated with advanced atherosclerosis (ESRD).

- MDCT excludes other etiologies while directing further management. ${ }^{4}$

- Flexible sigmoidoscopy can be helpful when clinical suspicion for ischemic colitis is very high but imaging is negative (non-occlusive mesenteric ischemia, NOMI).

- Aswanetmanee et al discuss the role of MDCT in the timely diagnosis of acute mesenteric ischemia in this issue of the Chronicles in which an elderly woman in the ICU with septic shock developed unexplained abdominal distension and ileus. An urgent MDCT demonstrated jejunal pneumatosis intestinalis and occlusion of the superior mesenteric artery. Prompt recognition led to successful embolectomy and small bowel resection.

\section{Biliary-pancreatic emergencies}

- Elevation of pancreatic enzymes in an ICU setting could be related to splanchnic hypoperfusion or acute pancreatitis (AP).

- Acute pancreatitis in an ICU setting requires detailed review of medications (drug-induced AP) and biliary ultrasound to look for chole (docho) lithiasis.

- Pain control, antibiotics, fluid resuscitation, and correction of electrolyte disorders will be the mainstay of management for biliary-pancreatic emergencies in the ICU. 
- $\quad$ Signs of biliary obstruction on labs and/or imaging warrant urgent decompression by ERCP.

- Percutaneous cholecystostomy is an alternative in unstable patients.

\section{Hepatic failure}

- Liver dysfunction in the ICU presents as jaundice with cholestasis (20\%) or hypoxic liver injury $(10 \%)$. Other causes include drug-induced hepatitis, decompensated chronic liver disease, and extra-hepatic biliary obstruction.

- $\quad$ Early recognition (liver enzymes, hepatitis serology, acetaminophen levels, imaging, and review of medications) and correction of precipitating factors will be the mainstay of therapy. Biliary obstruction is less common cause but is amenable quickly to endotherapy.

Corresponding Author: Sreeram Parupudi MD, FACP, FACG

Author Contact Information : srparupu@utmb.edu DOI: 10.12746/swrccc2013.0104.036
2. Müller T, Barkun AN, Martel M. Non-variceal upper GI bleeding in patients already hospitalized for another condition. Am J Gastroenterol 2009; 104:330-9.

3. Alhazzani W, Alenezi F, Jaeschke RZ, Moayyedi P, Cook DJ. Proton pump inhibitors versus histamine 2 receptor antagonists for stress ulcer prophylaxis in critically ill patients: a systematic review and meta-analysis. Crit Care Med 2013; 41:693-705.

4. Lee SS, Park SH. Computed tomography evaluation of gastrointestinal bleeding and acute mesenteric ischemia. Radiologic clinics of North America 2013; 51:29-43.

5. Hardt PD, Mayer K, Ewald N. Exocrine pancreatic involvement in critically ill patients. Curr Opin Clin Nutr Metab Care 2009; 12:168-74.

6. Barie PS, Eachempati SR. Acute acalculous cholecystitis. Gastroenterol Clin North Am. 2010;39:343-57

7. Bakkaloglu H, Yanar H, Guloglu R, Taviloglu K, Tunca F, Aksoy M, Ertekin C, Poyanli A. Ultrasound guided percutaneous cholecystostomy in high-risk patients for surgical intervention. World J Gastroenterol 2006;12):7179-82

8. Horvatits T, Trauner M, Fuhrmann V. Hypoxic liver injury and cholestasis in critically ill patients. Curr Opin Crit Care 2013; 19:128-32.

\section{REFERENCES}

1. Reintam Blaser A, Poeze M, Malbrain ML, Björck M, Oudemans-van Straaten HM, Starkopf J; Gastro-Intestinal Failure Trial Group. Gastrointestinal symptoms during the first week of intensive care are associated with poor outcome: a prospective multicentre study. Intensive Care Med 2013; 39:899-909. 